\title{
Estrogen receptor $\beta$ upregulated by IncRNA-H19 to promote cancer stem-like properties in papillary thyroid carcinoma
}

\author{
Mei Li ${ }^{1,2,3}$, Hui-Fang Chai ${ }^{1}$, Fei Peng1,2, Yu-Ting Meng ${ }^{1}$, Li-Zhi Zhang ${ }^{4}$, Lin Zhang ${ }^{5}$, Hong Zou', Qi-Lan Liang ',

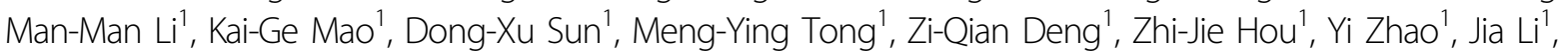 \\ Xiao-Chao Wang ${ }^{1}$, Sha-Sha Lv', Qing-Qing Zhang ${ }^{6}$, Xiao Yu' ${ }^{6}$, Eric W.-F. Lam $\mathbb{D}^{7}$, Quentin Liu ${ }^{1,2}$, Xiao-Nan Cui ${ }^{1}$ and \\ Jie $X u^{1}$
}

\begin{abstract}
Estrogen receptor $\beta$ (ERß) plays critical roles in thyroid cancer progression. However, its role in thyroid cancer stem cell maintenance remains elusive. Here, we report that ER $\beta$ is overexpressed in papillary thyroid cancer stem cells (PTCSCs), whereas ablation of ER $\beta$ decreases stemness-related factors expression, diminishes $\mathrm{ALDH}^{+}$cell populations, and suppresses sphere formation ability and tumor growth. Screening estrogen-responsive IncRNAs in PTC spheroid cells, we find that InCRNA-H19 is highly expressed in PTCSCs and PTC tissue specimens, which is correlated with poor overall survival. Mechanistically, estradiol (E2) significantly promotes H19 transcription via ER $\beta$ and elevates H19 expression. Silencing of H19 inhibits E2-induced sphere formation ability. Furthermore, H19 acting as a competitive endogenous RNA sequesters miRNA-3126-5p to reciprocally release ER $\beta$ expression. ER $\beta$ depletion reverses H19-induced stem-like properties upon E2 treatment. Appropriately, ERß is upregulated in PTC tissue specimens. Notably, aspirin attenuates E2-induced cancer stem-like traits through decreasing both $\mathrm{H} 19$ and ER $\beta$ expression. Collectively, our findings reveal that ERß-H19 positive feedback loop has a compelling role in PTCSC maintenance under E2 treatment and provides a potential therapeutic targeting strategy for PTC.
\end{abstract}

\section{Introduction}

Papillary thyroid carcinoma (PTC) is one of the most common thyroid neoplasms, which exhibits multicentricity in the thyroid gland and frequently metastasizes to the regional lymph nodes, thereby increasing both morbidity and mortality ${ }^{1}$. Increasing evidence indicates that papillary thyroid cancer stem cells (PTCSCs) play an

Correspondence: Jie Xu (xujie@dmu.edu.cn) or

Xiao-Nan Cui (cxn23@sina.com) or Quentin Liu (liuq9@mail.sysu.edu.cn)

${ }^{1}$ The First Affiliated Hospital, Institute of Cancer Stem Cell, Dalian Medical

University, Dalian, China

${ }^{2}$ State Key Laboratory of Oncology in South China, Cancer Center, Sun Yat-sen

University, Guangzhou, China

Full list of author information is available at the end of the article.

These authors contributed equally: Mei Li, Hui-Fang Chai, Fei Peng,

Yu-Ting Meng, Li-Zhi Zhang, Lin Zhang

Edited by A. Oberst important role in the progression of $\mathrm{PTC}^{2}$. For example, stem cell marker POU5F1 is highly expressed in $\mathrm{CD}_{4} 4^{+} /$ $\mathrm{CD}^{-} 4^{-}$subpopulation and tumorigenic thyrospheroid cells from $\mathrm{PTC}^{3}$. Tumor spheroids from PTC samples are more resistant to chemotherapeutics, including bortezomib, taxol, cisplatin, etoposide, doxorubicin, and vincristine, than non-spheroid PTC cells ${ }^{4}$. In PTC tissues, a positive correlation has been found between stemnessrelated gene expression and tumor, lymph node, metastasis (TNM) staging ${ }^{5}$. E2 is the most potent estrogen, which has a high affinity to estrogen receptor $\alpha(E R \alpha)$, estrogen receptor $\beta$ (ER $\beta)$, and Peroxisome proliferatoractivated receptor gamma (PPAR- $\gamma$ or PPARg) ${ }^{6,7}$. E2 enhances migration and invasion of PTC cells modulated

\section{(c) The Author(s) 2018}

(c) (i) Open Access This article is licensed under a Creative Commons Attribution 4.0 International License, which permits use, sharing, adaptation, distribution and reproduction cc) in any medium or format, as long as you give appropriate credit to the original author(s) and the source, provide a link to the Creative Commons license, and indicate if changes were made. The images or other third party material in this article are included in the article's Creative Commons license, unless indicated otherwise in a credit line to the material. If material is not included in the article's Creative Commons license and your intended use is not permitted by statutory regulation or exceeds the permitted use, you will need to obtain permission directly from the copyright holder. To view a copy of this license, visit http://creativecommons.org/licenses/by/4.0/. 
by E-cadherin, vimentin and MMP- $9^{8}$. Moreover, E2 stimulation elevates stemness-related gene expression in PTC cells and promotes motility and tumorigenicity of PTCSCs in vivo 9 . However, the molecular mechanism of estrogen regulating PTCSC maintenance remains poorly understood.

Long noncoding RNAs (lncRNAs) are a class of transcripts longer than 200 nucleotides but with no proteincoding potential, which play a crucial role in regulating cancer cell stemness. For example, recent studies show that knockdown of NEAT1 inhibits glioma stem cells progression via let-7e-NRAS axis ${ }^{10}$. LncRNA H19 increases core pluripotency factor LIN28 expression by blocking the bioactivity of let-7 to promote breast cancer stem cell maintenance ${ }^{11}$. LncRNA-DILC also attenuates liver cancer stem cell expansion through inhibiting the autocrine of IL6/STAT3 signaling ${ }^{12}$. In addition, ElncRNA1 is transcriptionally regulated by E2 through ER $\alpha$-estrogen response element pathway to promote epithelial ovarian cancer cell proliferation ${ }^{13}$. Furthermore, E2 treatment also drives Sp1 to increase lncRNA $M A L A T 1$ expression and epigenetically controls various physiological processes of osteosarcoma cells ${ }^{14}$. Although accumulating studies have indicated lncRNAs play important roles in maintaining CSCs and could be regulated by estrogen signaling in diverse cancers, little is known about the mechanism by which IncRNAs modulate E2-induced PTCSCs.

Emerged evidence has suggested that estrogen receptors (ERs) play pivotal roles in the pathogenesis of PTC. For example, ER $\alpha$ can trigger autophagy via activating ROS and ERK1/2 pathways to promote cell proliferation and inhibit apoptosis in PTC cells ${ }^{15}$. ER $\beta$ is associated with apoptosis and growth inhibition, providing a negative correlation with mutant p53 in female PTC patients of reproductive $\operatorname{age}^{16}$. Moreover, reciprocal interactions between ER $\beta$ and PPARg significantly inhibit PTC cell proliferation and migration, while ER $\alpha$ offsets the inhibitory effect of PPARg on cellular functions ${ }^{17}$. In addition, ER-elevated OCT4 expression promotes self-renewal of the human breast cancer stem cells ${ }^{18}$. Furthermore, thyroid stem and progenitor cells derived from nodular goiters express higher levels of ER $\alpha$ and ER $\beta$ compared with the differentiated thyrocytes ${ }^{19}$. However, the underlying molecular mechanism whereby ER promotes PTC stemness is again still unclear.

Here, we demonstrate that ER $\beta$ is enriched in PTCSCs and contributes to PTCSC maintenance. Meanwhile, lncRNA H19 is highly expressed in PTCSCs and PTC tissue specimens. E2 promotes $H 19$ transcription via ER $\beta$. Ablation of $H 19$ antagonizes E2-induced cancer stem-like properties in PTC cells. Moreover, ER $\beta$ is elevated through $H 19 /$ miR-3126-5p signaling axis. ER $\beta$ depletion markedly reverses H19-mediated PTC stem-like capability under E2 treatment. ER $\beta$ is also upregulated in PTC tissue specimens. Importantly, aspirin suppresses E2-induced cancer stem-like characteristics through decreasing both ER $\beta$ and $H 19$ expression. Taken together, our study identifies a novel mechanism of E2-induced ER $\beta-H 19$ positive regulatory circuit in PTCSC maintenance, providing a potential therapeutic strategy for PTC.

\section{Results \\ ER $\beta$ contributes to PTCSCs}

As the effect of estrogen is predominantly mediated through ER $\alpha$ and ER $\beta$, we first examined whether ER $\alpha$ and ER $\beta$ are involved in PTC stemness. To this end, we performed sphere formation assay to enrich PTCSCs. The mRNA levels of ESR1 and ESR2 were compared between spheroid and monolayer cells. The results showed that ESR2 mRNA expression was remarkably elevated in both TPC-1 spheroid cells and K-1 spheroid cells compared to their monolayer counterparts (Fig. 1a). Spheroid cells exhibited much higher mRNA expression of stemnessrelated factors, including NANOG, SOX2, and POU5F1, in both TPC-1 and K-1 cells (Fig. 1b). Conversely, the spheroid cells exhibited a relative reduction of thyroid differentiation markers including Thyroglobulin $(T g)$ and thyroid stimulating receptor (TSHR) in both TPC-1 and K-1 cells (Supplementary Figure 1a). Next, we measured ER $\beta$ and stemness-related protein NANOG in the same paraffin-embedded tissue specimens and found that ER $\beta$ was positively correlated with NANOG expression in the PTC tissues (Fig. 1c, d). Furthermore, ablation of ER $\beta$ by siRNAs significantly decreased NANOG and OCT4 protein expression in both $\mathrm{K}-1$ cells (Fig. 1e) and TPC-1 cells (Supplementary Figure 1b). ER $\beta$ knockdown diminished $\mathrm{ALDH}^{+}$cell populations in both K-1 cells (Fig. 1f) and TPC-1 cells (Supplementary Figure 1c). In addition, ER $\beta$ was knocked down by shRNA in both K-1 (Supplementary Figure 1d) and TPC-1 cells (Supplementary Figure 1e). Sphere formation assay showed that ER $\beta$ depletion significantly decreased spheroid numbers and diameters in both K-1 (Fig. 1g) and TPC-1 (Supplementary Figure 1f) cells. Moreover, the effect of ER $\beta$ on tumorigenesis was further examined in nude mice by injecting with control $\mathrm{K}-1$ cells (NTC; non-targeting control), shER $\beta-1 \mathrm{~K}-1$ cells (shER $\beta-1)$ and $\operatorname{shER} \beta-2 \mathrm{~K}-$ 1 cells (shER $\beta-2)$. As shown in Fig. 1h, the tumor volumes in shER $\beta-1$ and shER $\beta-2$ groups were apparently smaller than NTC group, indicating that ER $\beta$ is critical for PTCSC maintenance.

\section{H19 is highly expressed in PTCSCs and PTC tissue specimens}

The fact that lncRNAs can be induced by estrogen and are widely involved in cancer stem cell maintenance prompted us to investigate whether lncRNA plays a 
a

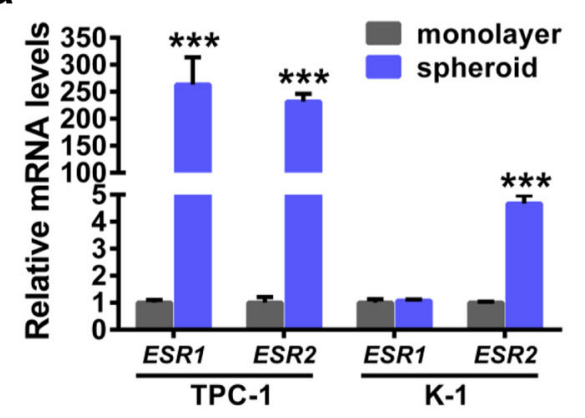

C
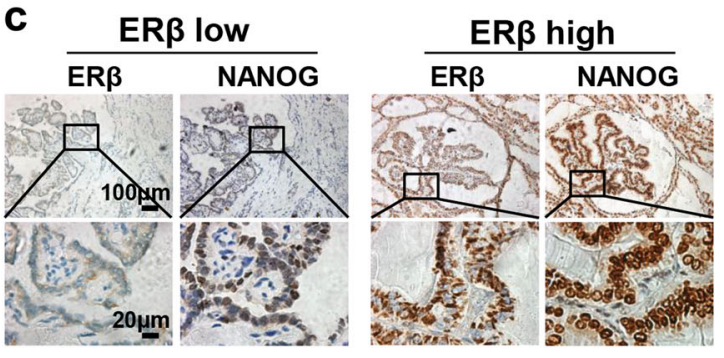

e

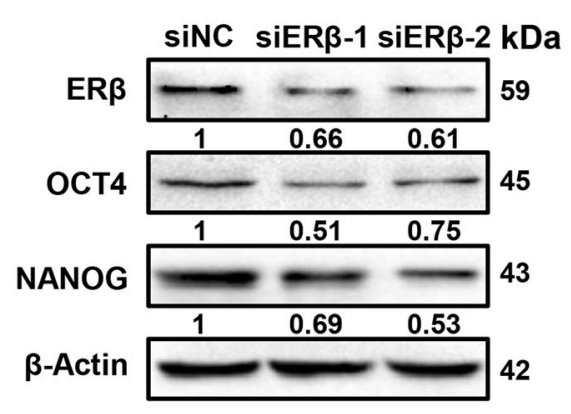

g
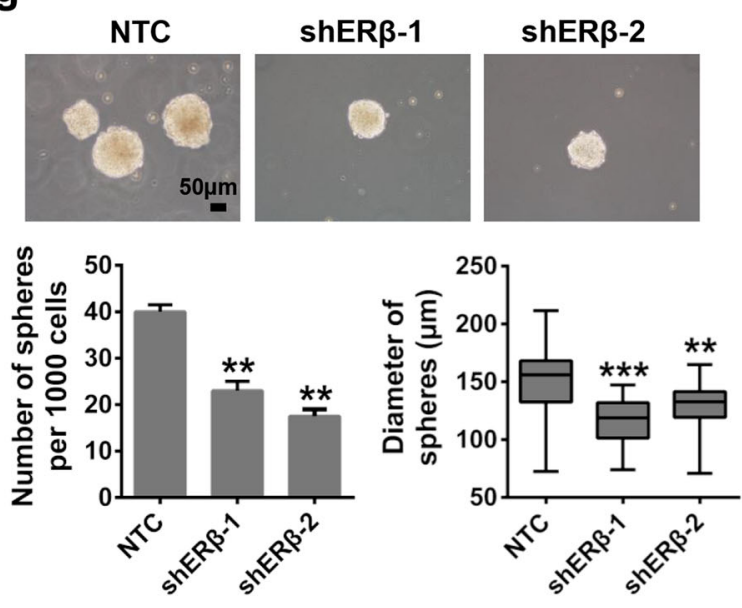

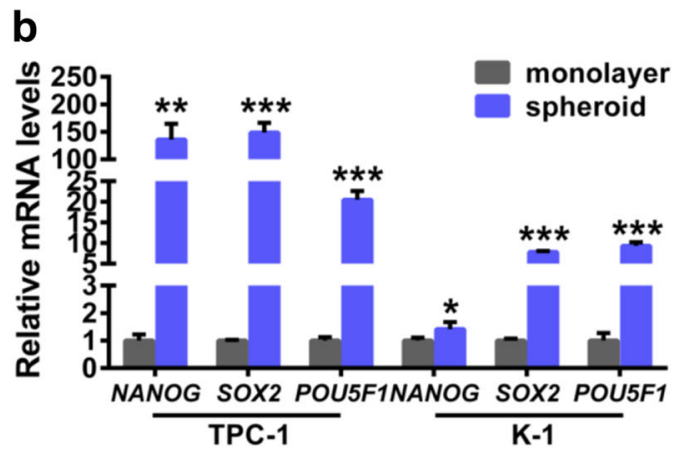

d

\begin{tabular}{|c|c|c|c|}
\hline \multirow{2}{*}{$E R \beta$} & \multicolumn{2}{|c|}{ NANOG } & \multirow[b]{2}{*}{ Total } \\
\hline & H-score $<57$ & H-score $\geq 57$ & \\
\hline H-score $<67$ & 22 & 3 & 25 \\
\hline H-score $\geq 67$ & 5 & 11 & 16 \\
\hline Total & 27 & 14 & 41 \\
\hline
\end{tabular}

f

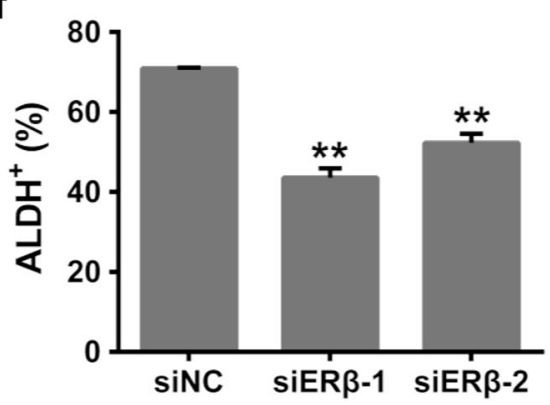

h
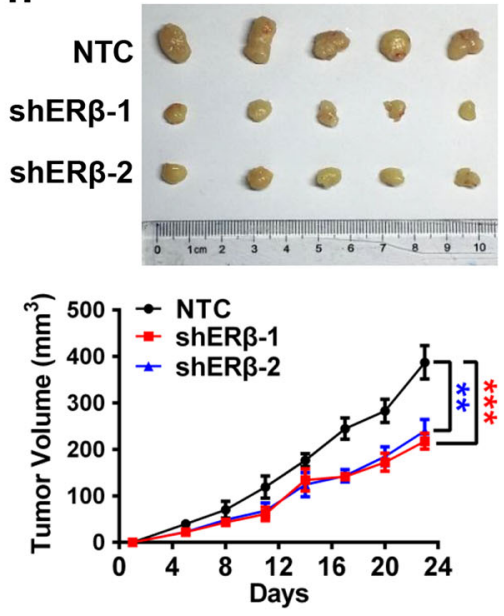

Fig. 1 (See legend on next page) 
(see figure on previous page)

Fig. 1 ER $\beta$ contributes to papillary thyroid CSCs. a ESR1 and ESR2 mRNA expression in the spheroid cells and monolayer cells of TPC-1 cells and K1 cells were analyzed by RT-qPCR. Data were shown as means \pm SD $\left(n=3,{ }^{* * *} P<0.001\right)$. b A panel of core pluripotency factors (NANOG, SOX2, and POU5F1) were measured between spheroid cells and monolayer cells from both TPC-1 cells and K-1 cells. Data were shown as means \pm SD $(n=3$, ${ }^{*} P<0.05,{ }^{* *} P<0.01$ and $\left.{ }^{* *} P<0.001\right)$. c PTC tissue specimens were subjected to IHC staining by ER $\beta$ and NANOG antibodies. Representative images were presented. Scale bar, 100 or $20 \mu \mathrm{m}$. $\mathbf{d}$ The correlation between the ER $\beta$ and NANOG expression in PTC tissues from 41 patients. ${ }^{* * *} P<0.001$. e The protein levels of ERß and stemness-related factors NANOG and OCT4 were measured in siNC and siER $\mathrm{K}-1$ cells. $\beta$-Actin acted as the loading control. $\mathbf{f}$ The proportions of $\mathrm{ALDH}^{+}$cells were compared between siNC and siER $\beta$ K-1 cells. $\mathbf{g}$ Sphere formation ability was performed in ER $\beta$ depletion K-1 cells. Representative images were presented (up), the scale bar represents $50 \mu \mathrm{m}$. The numbers and size of spheres were counted after culture for 10 days (down). Data were shown as means $\pm \operatorname{SD}\left(n=3,{ }^{*} P<0.01\right.$ and $\left.{ }^{* * *} P<0.001\right)$. h BALB/c nude male mice $(n=5)$ were subcutaneously inoculated with equal number of single cells $\left(1 \times 10^{6}\right.$ cells). The tumors were harvested at day 23 after injection (upper panel). Tumor volumes were monitored as described (lower panel)

critical role in regulating PTCSCs. To this end, we compared the expression levels of 13 potential estrogenresponsive lncRNAs (UCA1, H19, TC1500845, TC0101441, ROR, MALAT1, NEAT1, SRA1, HOTAIR, BC200, RP11-445H22.4, TC01000223 and TC01001686) between spheroids and monolayer cells ${ }^{13,14,20-27}$. The results showed that $H 19$ was the highest expressing lncRNA in spheroids as well as the highest differentially expressed lncRNA when compared with monolayer cells (Fig. 2a, b). Consistently, H19 expression was much higher in spheroid cells than in monolayer cells through FISH assay (Fig. 2c). Moreover, H19 expression level was significantly higher in PTC tissue specimens compared with the adjacent tissue specimens (Fig. 2d, e). Furthermore, the Kaplan-Meier survival analysis demonstrated that high $H 19$ levels were a strong indicator for poor overall survival of thyroid cancers in TCGA database (Fig. 2f), suggesting a remarkably unfavorable prognosis and shorter lifespan. In summary, H19 is highly expressed in PTCSCs and PTC tissue specimens.

\section{H19 depletion reverses E2-induced stem-like properties in PTC cells}

To further explore whether $\mathrm{H} 19$ is involved in E2induced PTCSC maintenance, we performed sphere formation assay upon treatment with E2 in PTC cells. Both sphere numbers and diameters were markedly elevated upon E2 treatment in both TPC-1 cells and K-1 cells (Supplementary Figure 2a and b). In addition, we conducted RT-qPCR assay to further explore the effects of E2 on PTC stemness. E2 increased substantially the mRNA expression levels of stemness-related factors, including NANOG, SOX2 and POU5F1, in both TPC-1 cells and K-1 cells (Supplementary Figure 2c). PTC cells were also treated with various doses $(0,10$, and $50 \mathrm{nM})$ of E2 for 36 h. As shown in Fig. 3a, E2 significantly increased H19 RNA levels of PTC cells in a dose-dependent manner. Consistently, H19 RNA expression was also elevated by E2 treatment $(50 \mathrm{nM})$ in a time-dependent manner in both TPC-1 cells and K-1 cells (Fig. 3b). Furthermore, E2 promoted $H 19$ pre-RNA expression (Fig. 3c) and increased ESR2 but not ESR1 mRNA expression (Supplementary Figure 2d) in both TPC-1 and K-1 cells, which prompted that E2 regulates $H 19$ transcription through $E R \beta$. Indeed, silencing of ER $\beta$ significantly decreased both pre-H19 and H19 RNA levels (Fig. 3d). To determine transcription activity of $H 19, H 19$ promoter sequence (H19-WT) and the H19 promoter sequence with truncated ERE segment (H19-Del) and the H19 promoter with ERE domain (H19-Mut) were cloned into the pGL3 vector (Supplementary Figure 2e), respectively. E2 treatment promoted H19-WT luciferase activity, while it had no effects on H19-Del and H19-Mut activities (Fig. 3e). Conversely, depletion of ER $\beta$ dramatically attenuated H19-WT luciferase activity, whereas it caused no changes in H19-Del and H19-Mut activities (Supplementary Figure $2 \mathrm{f}$ and Fig. $3 \mathrm{f}$ ). These data show that E2 promotes stem-like traits and increases $H 19$ transcription in PTC cells.

We next investigated whether $H 19$ mediated E2-derived cancer stem-like traits in PTC cells. To achieve this, H19 was knocked down by shRNA in TPC-1 cells and K-1 cells (Supplementary Figure 2g). Next, we performed sphere formation assay and observed that E2 treatment increased spheroid numbers and diameters, while $H 19$ knockdown attenuated sphere formation capacity. Depletion of H19 significantly reversed E2-induced sphere formation capability in both K-1 cells (Fig. 3g) and TPC-1 cells (Supplementary Figure $2 \mathrm{~h}$ ). These data provide evidence to suggest that $H 19$ plays an essential role in promoting cancer stem-like characteristics induced by E2 in PTC cells.

\section{ER $\beta$ regulated by $H 19 / \mathrm{miR} 3126-5 p$ signaling axis promotes cancer stem-like properties upon E2 treatment}

We next investigated the molecular mechanism whereby ER $\beta$ regulates $H 19$-induced stem-like properties upon E2 treatment. We firstly measured the expression of ESR2 in the H19-knockdown (shH19) PTC cells. The result showed that there were no significant changes in ESR2 mRNA levels in the PTC cells upon H19 knockdown (Supplementary Figure 3a), while H19 depletion 

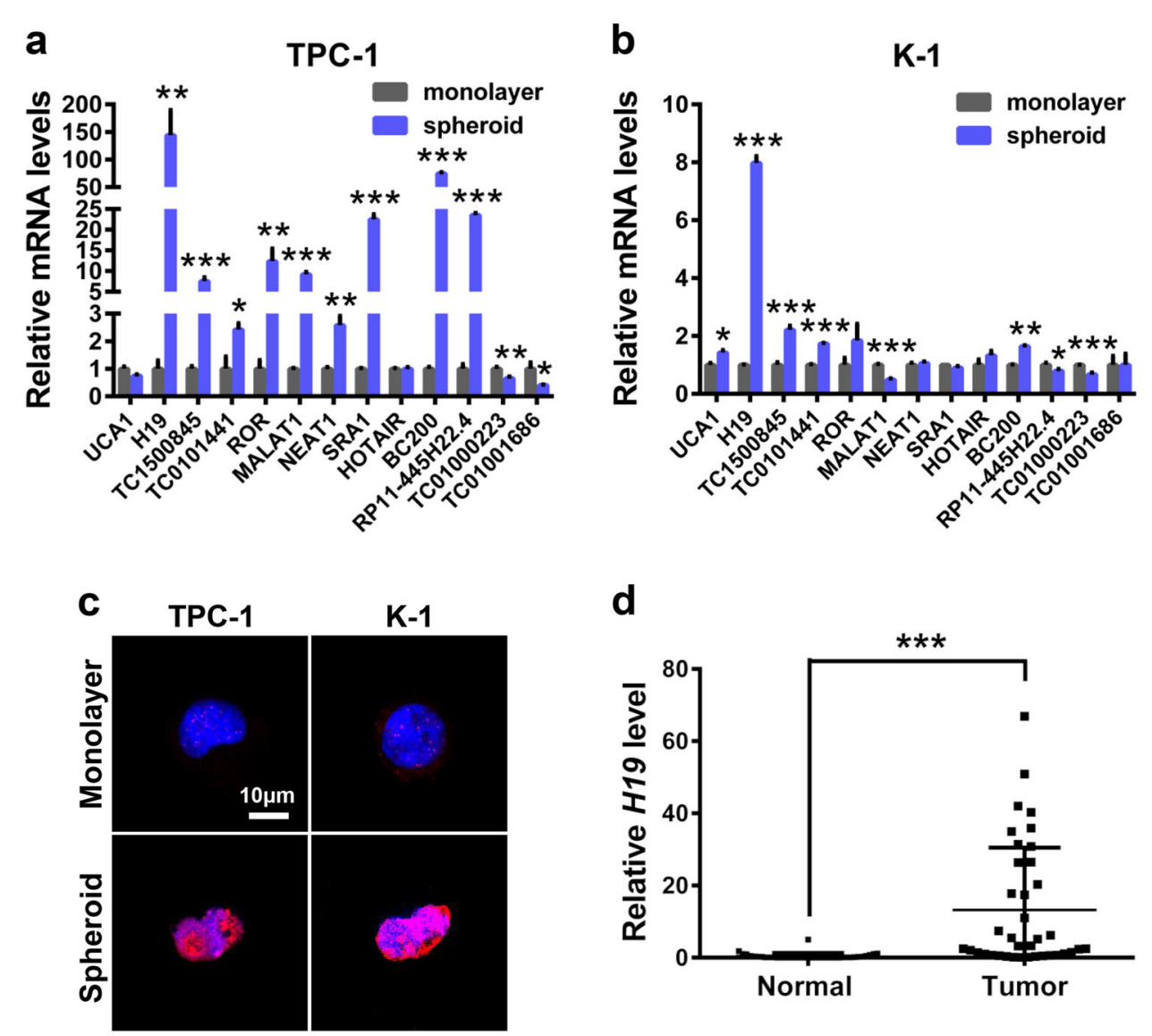

$\mathrm{K}-1$

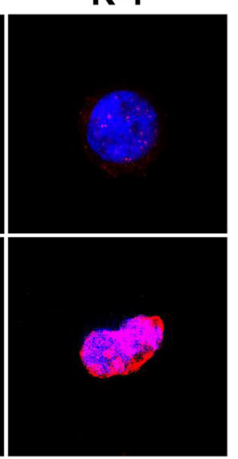

d

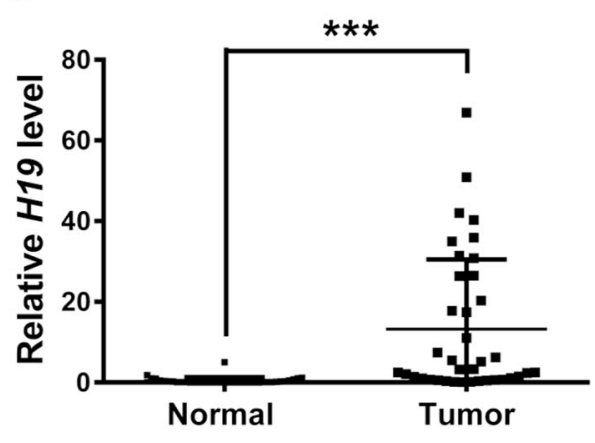

e

f
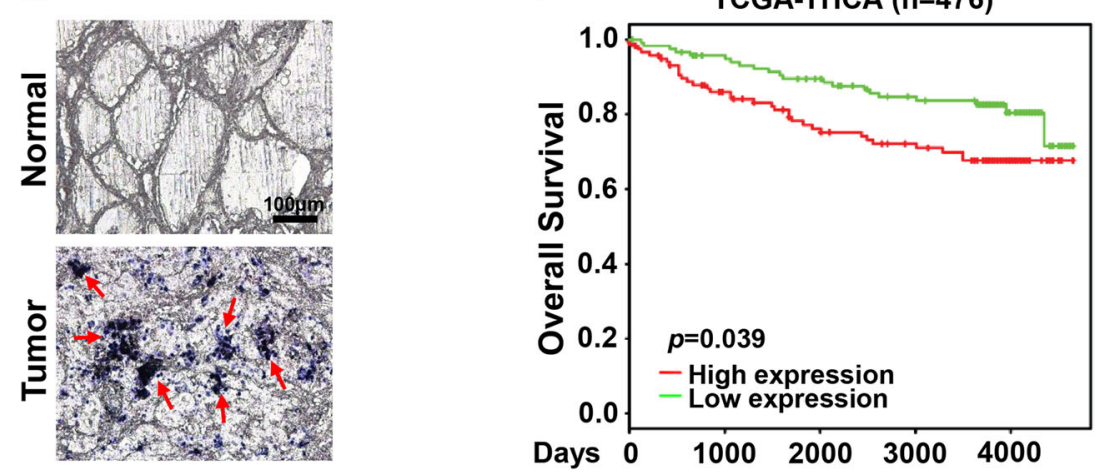

Fig. $2 \mathrm{H} 19$ expression is elevated in PTCSCs and PTC tissue specimens. a RT-qPCR analysis of the indicated IncRNA levels in the TPC-1 spheroid cells and TPC-1 monolayer cells. Data were shown as means \pm SD $(n=3){ }^{*} P<0.05$, ${ }^{*} P<0.01$ and ${ }^{* *} P<0.001$. b RT-qPCR analysis of the indicated IncRNA levels in the K-1 spheroid cells and K-1 monolayer cells. Data were shown as means \pm SD $(n=3){ }^{*} P<0.05$, ${ }^{* *} P<0.01$ and ${ }^{* * *} P<0.001$. c The in situ expression of H19 RNA was detected by FISH assay. The red fluorescent represents H19 RNA probe, and the blue fluorescent signal represents nuclear DNA counterstained with DAPI. The scale bar represents $10 \mu \mathrm{m}$. $\mathbf{d}$ H19 expression in PTC tissues and adjacent normal tissues were analyzed by RT-qPCR assay $(n=38)$. The relative $H 19$ level was normalized to ACTB. The statistical difference was analyzed using the paired $t$-test. ${ }^{* * *} P<0.001$. e In situ analysis with a DIG-labeled H19 probe in PTC tissue specimens and adjacent normal tissue specimens. The scale bar represents $100 \mu \mathrm{m}$. f Kaplan-Meier overall survival plots of 476 thyroid cancer patients created using PROGgeneV2, data set from TCGA-THCA. Patients were classified into H19-high and H19-low subgroups and analyzed as indicated 
a

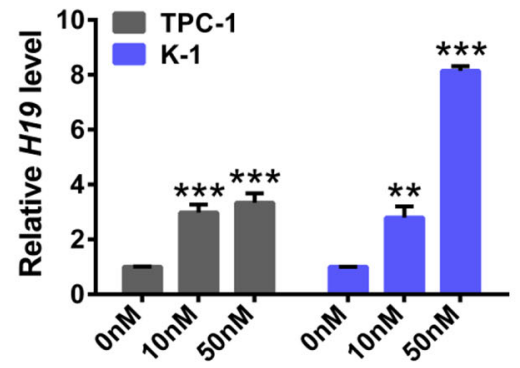

C

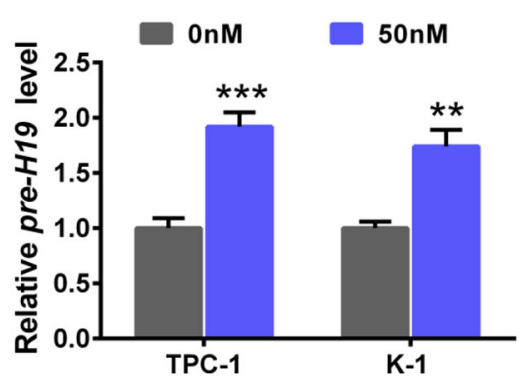

e

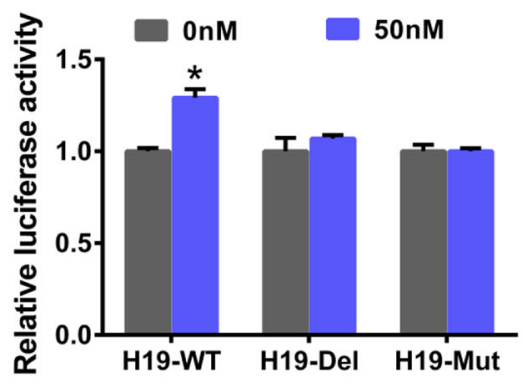

g
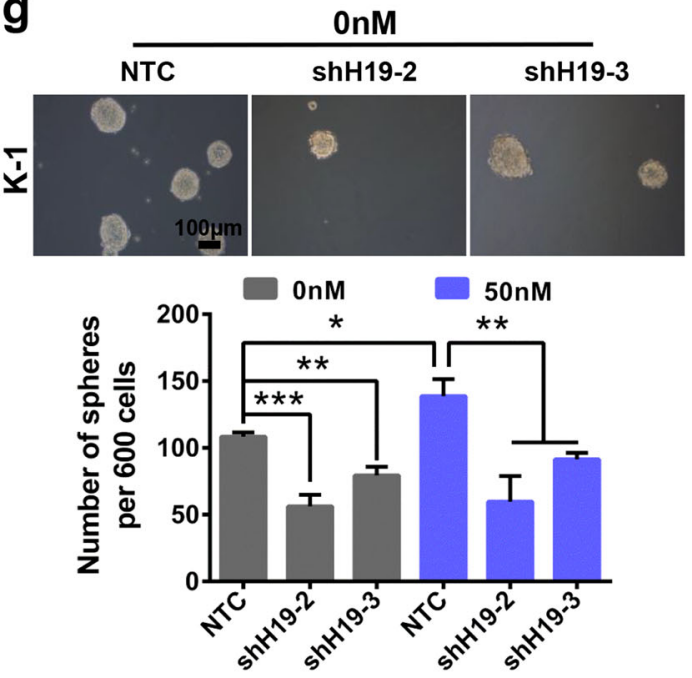

b

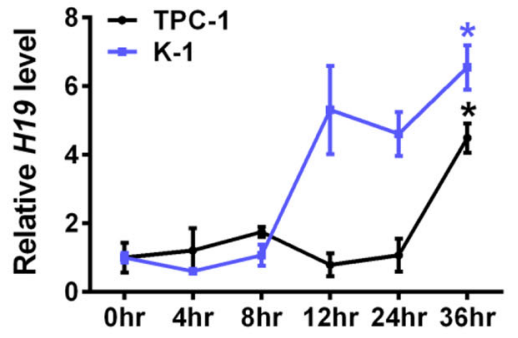

d

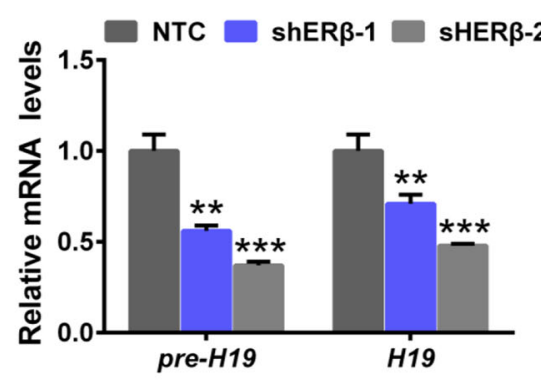

f
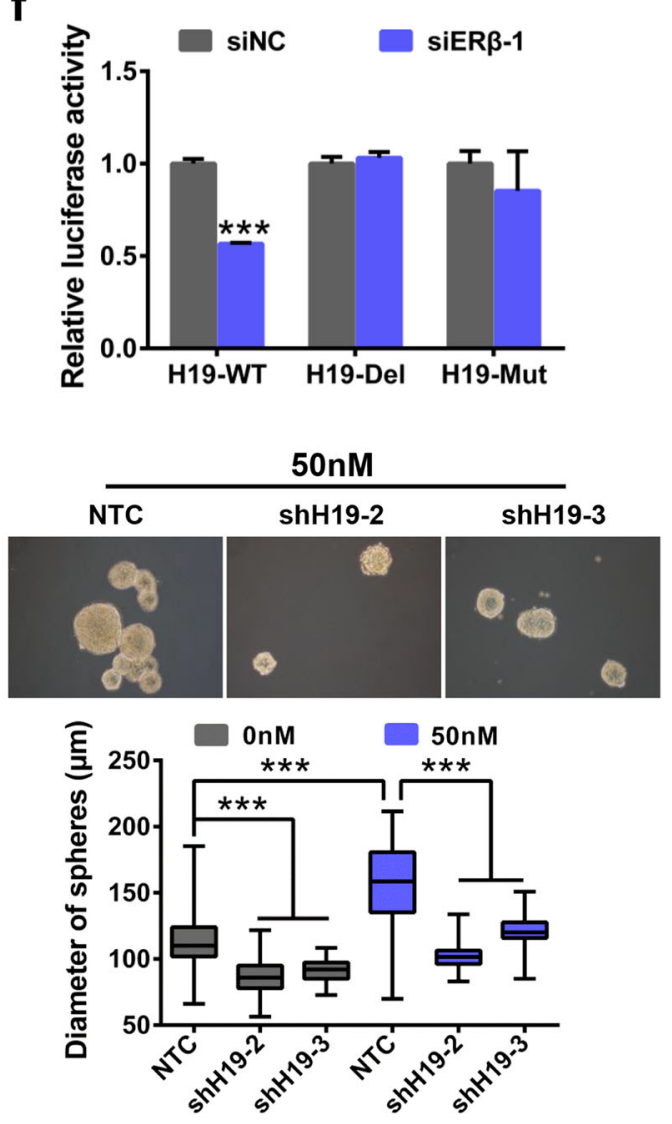

Fig. 3 (See legend on next page.) 
(see figure on previous page)

Fig. $3 \mathbf{H 1 9}$ mediates E2-induced stem-like properties in PTC cells. a TPC-1 and K-1 cells were treated with various concentrations $(0,10$, and 50 $\mathrm{nM}$ ) of E2 for $36 \mathrm{~h}$. Total RNA was extracted and subjected to detect H19 expression by RT-qPCR analysis. The relative H19 level was normalized to ACTB. Data were shown as means \pm SD. $\left(n=3,{ }^{*} P<0.01\right.$ and $\left.{ }^{* *} P<0.001\right)$. b TPC -1 and $\mathrm{K}-1$ cells were treated with $50 \mathrm{nM} E 2$ for $0,4,8,12,24,36 \mathrm{~h}$. Total RNA was extracted and subjected to detect $H 19$ expression by RT-qPCR analysis. The relative $H 19$ level was normalized to ACTB. Data were shown as means $\pm \mathrm{SD}$. $\left(n=3,{ }^{*} P<0.05\right)$. c TPC-1 and K-1 cells were treated with E2 $(50 \mathrm{nM})$ for $36 \mathrm{~h}$. Total RNA was extracted and subjected to detect pre-H19 expression by RT-qPCR. The relative pre-H19 levels were normalized to ACTB. Data were shown as means \pm SD. $\left(n=3,{ }^{* *} P<0.01\right.$ and ${ }^{* * *} P<$ 0.001). d Total RNA was extracted in NTC, shERß-1, shERß-2 K-1 cells. Pre-H19 and H19 were detected by RT-qPCR assay. The relative RNA levels were normalized to $A C T B$. Data were shown as means $\pm S D\left(n=3\right.$, ${ }^{* *} P<0.01$ and $\left.{ }^{* * *} P<0.001\right)$. e pGL3-EV, pGL3-H19-WT, -H19-Del, or -H19-Mut along with pRL-SV40 were transfected into K-1 cells with E2 treatment. After $24 \mathrm{~h}$, dual-luciferase reporter assays were performed $\left(n=3,{ }^{*} P<0.05\right)$. f siNC and siERß were co-transfected into K-1 cells with pGL3-EV, pGL3-H19-WT, -H19-Del, or -H19-Mut along with pRL-SV40. After 24 h, dual-luciferase reporter assays were performed $\left(n=3,{ }^{* *} P<0.001\right)$. g Sphere formation abilities of K-1 under different conditions were compared. Representative images were presented, the scale bar represents $100 \mu \mathrm{m}$. The numbers and size of spheres were counted after culture for 10 days. Data were shown as means \pm SD. $\left(n=3,{ }^{*} P<0.05,{ }^{* *} P<0.01\right.$ and $\left.{ }^{* * *} P<0.001\right)$

decreased ER $\beta$ protein levels in K-1 cells (Fig. 4a). E2 treatment increased ER $\beta$ expression, which could be attenuated by silencing $\mathrm{H} 19$ in $\mathrm{K}-1$ cells (Fig. $4 \mathrm{~b}$ and Supplementary Figure 3b). To confirm whether H19 acting as a competitive endogenous sponge interacts with miRNAs to release ER $\beta$ expression, we searched for miRNAs that interact with $H 19$ and also target $3^{\prime} \mathrm{UTR}$ region of ESR2 by bioinformatic tools. The mimics of six identified miRNAs (Supplementary Figure 3c), including miR-4268, miR-3198, miR-876-3p, miR-1976, miR-3126$5 \mathrm{p}$ and miR-127-5p, were transfected into K-1 cells. The results showed that the miR-3126-5p mimetic significantly decreased ER $\beta$ protein expression (Supplementary Figure 3d), while miR-3126-5p inhibitor remarkably increased ER $\beta$ protein level (Supplementary Figure 3e). Moreover, wild-type ESR2 3'UTR sequence including the putative miRNA-3126-5p response element (MRE) and the MRE mutant were cloned into the psiCHECK2 vector to give rise to psi-ESR2-WT and psiESR2-Mut (Supplementary Figure 3f), respectively. The psi-ESR2-WT and psi-ESR2-Mut vectors were then independently transfected into $\mathrm{K}-1$ cells together with miR-3126-5p mimic or inhibitor in parallel with negative controls. The results showed that miR-3126-5p mimic repressed, but miR-3126-5p inhibitor increased, the relative luciferase activity of reporter psi-ESR2-WT, whereas both of them had no effects on psi-ESR2-Mut (Fig. 4c, d). Consistently, miR-3126-5p released by shH19 decreased ER $\beta$ expression, which could be rescued by the miR-3126$5 p$ inhibitor in K-1 cells (Fig. 4e). Furthermore, we found that in K-1 cells the relative luciferase activity of psiESR2-WT (sensor) was induced by increasing amounts of wide-type $H 19$ (H19-WT, sponge of miR-3126-5p), but not by $\mathrm{H} 19$ with the miR-3126-5p binding sites mutated (H19-Mut) in a dose-dependent manner (Fig. 4f).

Next, H19-overexpressing plasmid was transiently transfected into shER $\beta$ or non-targeting control (NTC) transduced K-1 cells (Supplementary Figure 3g). Sphere formation assay showed that E2 treatment or H19 overexpression significantly promoted sphere formation capacities, whereas depletion of ER $\beta$ restricted E2- or H19-induced stem-like properties in $\mathrm{K}-1$ cells (Fig. 4g). These results support the idea that $H 19 / \mathrm{miR} 3125-5 \mathrm{p}$ regulates stem-like properties upon E2 treatment through ER $\beta$ in PTC cells.

\section{ER $\beta$ is upregulated in PTC tissue specimens}

To further examine the ER $\beta$ expression in clinical samples, we performed immunohistochemistry (IHC) staining to measure ER $\beta$ in PTC tissue specimens and the corresponding adjacent tissues. ER $\beta$ exhibited higher expression in tumor tissue specimens compared to the corresponding adjacent tissues (Fig. 5a). Next, we assessed the expression of ER $\beta$ using western blotting assay in another six pairs of tumor tissue specimens, and similar ER $\beta$ expression patterns were also observed (Fig. 5b). These results demonstrate that ER $\beta$ is upregulated in PTC tissue specimens.

\section{Aspirin suppresses E2-induced cancer stemness through decreasing $\mathrm{H} 19$ and ER $\beta$ expression}

Previous studies have demonstrated that aspirin (ASA) possesses antineoplastic actions against a wide range of solid tumors. Upon ASA treatment, H19 expression was dramatically decreased in both dose-dependent (Fig. 6a) and time-dependent (Fig. 6b) manners. ASA also resulted in a decrease in the protein expression level of ER $\beta$ in a time-dependent manner (Fig. 6c). Moreover, H19-overexpressing plasmid in parallel with empty vector $(\mathrm{EV})$ was transiently transfected into K-1 cells under ASA treatment. The expression of ER $\beta$ was rescued by overexpression of $\mathrm{H19}$ in the presence of ASA (Fig. 6d and Supplementary Figure 4a). Notably, E2-enhanced sphere formation abilities were substantially attenuated by ASA in $\mathrm{K}-1$ cells (Fig. 6e). In conclusion, these results reveal that H19 mediates E2-induced stem-like properties 
a

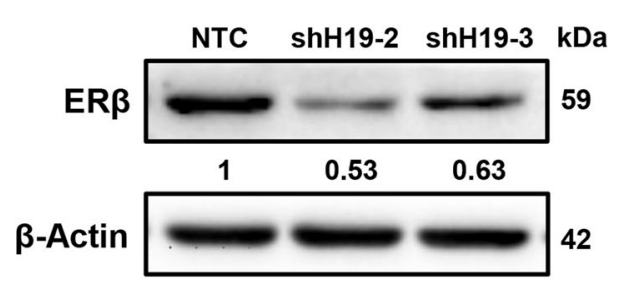

C

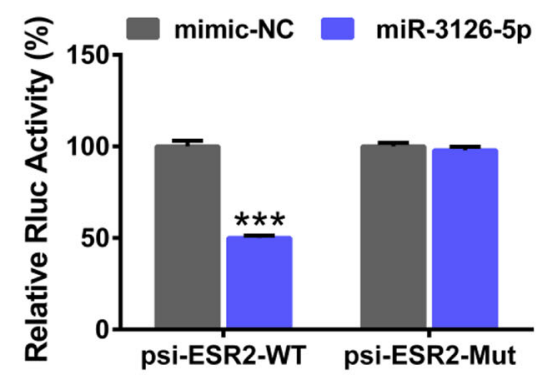

e

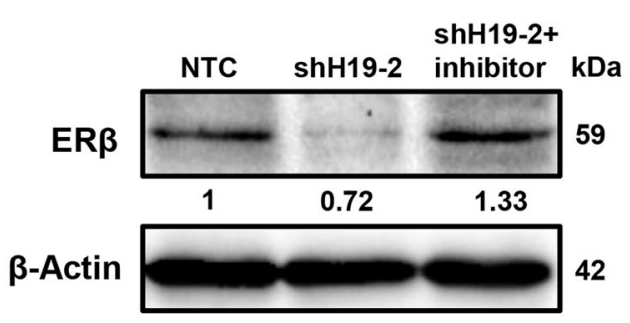

g
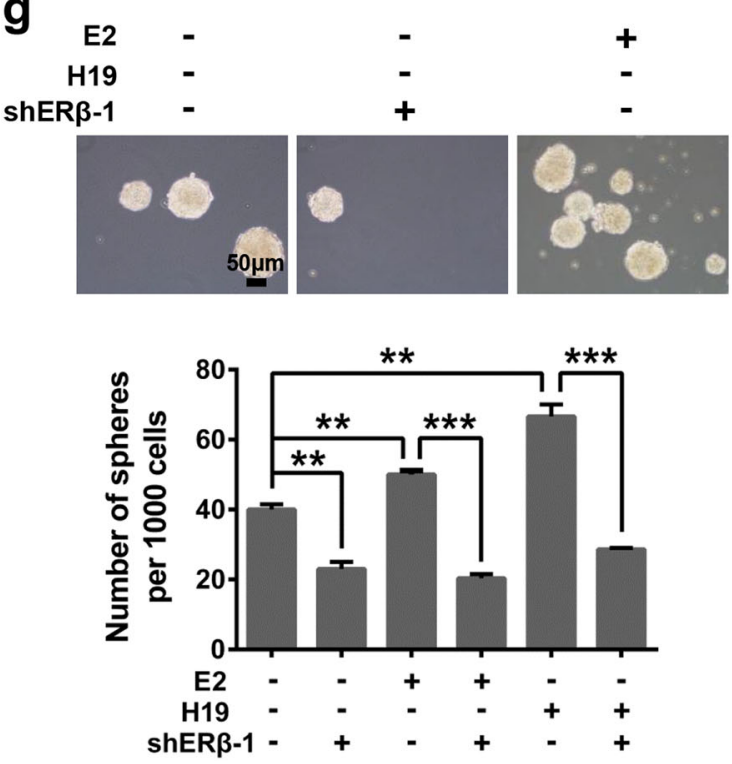

b

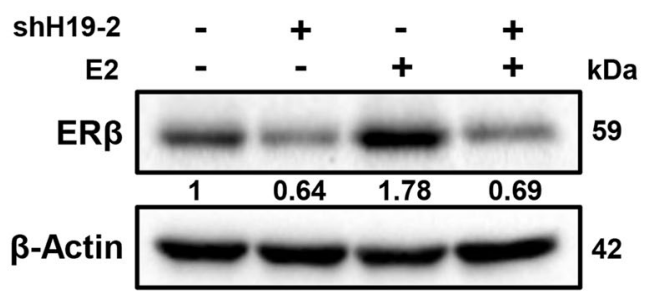

d

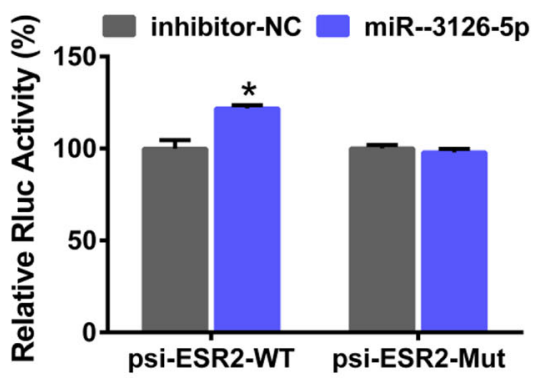

f

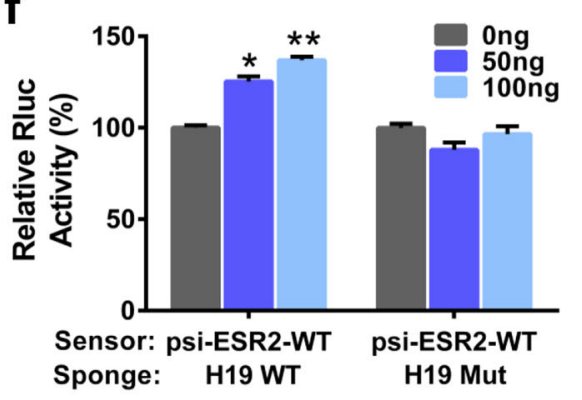

\footnotetext{
Fig. 4 (See legend on next page.)
} 


\begin{abstract}
(see figure on previous page)
Fig. 4 H19/miR-3126-5p/ER $\beta$ regulated stem-like properties under E2 treatment in PTC cells. a ER $\beta$ expression was analyzed by western blotting in K-1 shH19 cells and NTC cells. $\beta$-Actin acted as the loading control. b K-1 (shH19-2) cells and NTC cells were treated with or without E2 for $36 \mathrm{~h}$. ER $\beta$ expression was analyzed by western blotting. $\beta$-Actin acted as the loading control. c The psi-ESR2-WT or -Mut, and miR-3126-5p mimic along with negative control (NC) were co-transfected into K-1 cells. The regulation of ESR2 by miR-3126-5p was measured by luciferase assay ( $n=3$, $\left.{ }^{* * *} P<0.001\right)$. d The psi-ESR2-WT or -Mut, and miR-3126-5p inhibitor in parallel with negative control (NC) were co-transfected into K-1 cells. The regulation of ESR2 by miR-3126-5p was measured by luciferase assay $\left(n=3,{ }^{*} P<0.05\right)$. e ERß expression was examined in shH19 cells and miR-3126$5 p$ inhibitor transfected shH19 cells compared with NTC K-1 cells. $\beta$-Actin was used as the loading control. $\mathbf{f}$ K-1 cells were transfected with miR-3126$5 p$ sensor (psi-ESR2-WT) together with 0,50, and $100 \mathrm{ng}$ of wild-type H19 (WT) or mutant H19 (Mut) plasmids, and dual-luciferase reporter activity was analyzed $\left(n=3,{ }^{*} P<0.05,{ }^{*} P<0.01\right)$. g Sphere formation abilities of shER $\beta$ K-1 cells and NTC cells under different conditions were compared. Representative images were presented, counted at 20x, the scale bar represents $50 \mu \mathrm{m}$. The numbers and size of spheres were counted after culture for 10 days. Data were shown as means \pm SD. $\left(n=3,{ }^{*} P<0.05\right.$, ${ }^{* *} P<0.01$ and $\left.{ }^{* *} P<0.001\right)$
\end{abstract}

through upregulating ER $\beta$ expression in PTC cells, which can be inhibited by ASA (Fig. 6f).

\section{Discussion}

In this study, we demonstrate that the induction of ER $\beta$ expression by $H 19$ is critical for PTCSC maintenance. In agreement, ER $\beta$ is highly expressed in PTCSCs and promotes PTC stem-like properties (Fig. 1). Screening estrogen-responsive lncRNAs in spheroid cells, we observe that $\mathrm{H} 19$ is significantly elevated in PTCSCs and PTC tissue specimens (Fig. 2). H19 transcription can be activated by ER $\beta$ under E2 treatment, and ablation of $H 19$ reverses E2-induced stem-like traits in PTC cells (Fig. 3). Moreover, H19 sponges miR-3126-5p to release ER $\beta$ expression, and silencing of ER $\beta$ remarkably inhibits E2/ H19-induced stem-like properties in PTC cells (Fig. 4). In concordance, ER $\beta$ also displays a higher expression level in PTC tissue specimens (Fig. 5). Notably, aspirin can antagonize E2-induced stem-like properties through suppressing $H 19$ and thereby ER $\beta$ expression (Fig. 6).

Accumulating studies have revealed correlations between thyroid cancer incidence and ovulatory cycles, pregnancy, and lactation suppressant ${ }^{28,29}$, which suggest a pivotal role of sex hormones, in particular estrogen, in PTC progression. For example, E2 has been shown to stimulate thyroid cancer cell proliferation through increasing the anti-apoptotic protein $\mathrm{BCL}-2$ and decreasing the pro-apoptotic BAX in an ERK1/2-dependent manner ${ }^{30}$. E2 also promotes adhesion, migration, and invasion capabilities via $\beta$-catenin in thyroid cancer cells $^{31}$. Recent studies have reported that estrogens are involved in elevating hematopoietic stem-cell self-renewal capabilities in female subjects and more specifically during pregnancy ${ }^{32}$. Although E2 promotes sphere formation abilities, elevates tumorigenicity of PTCSCs and decreases the expression of the differentiation markers in thyroid progenitor cells ${ }^{9,19}$. The detailed mechanisms in which estrogen modulates PTCSCs are still unknown. Recent study reported that H19 is downregulated in PTC tissues and PTC cell lines ${ }^{33}$. In our study, only clinical specimens of reproductive age were selected as candidates, which were considered to have high estrogen levels. We found that $H 19$ is upregulated in PTC tissues. In addition, H19 was elevated in PTCSCs enriched by sphere formation which indicates $H 19$ plays an important role in PTC stemness. Conversely, silencing of H19 significantly reverses E2-induced PTC stem-like properties (Fig. 3). $H 19$ has been reported to be upregulated by E2 via the estrogen-ER $\alpha-H 19$ signaling axis in breast tumors ${ }^{20,34}$. Furthermore, CLIM interacting with ER $\alpha$ binds to H19 locus and promotes $H 19$ expression, which negatively regulates corneal epithelial proliferation ${ }^{35}$. However, the detail mechanism on how ER regulates $H 19$ expression remains unclear. Our results show that E2 treatment increases lncRNA $H 19$ transcription via ER $\beta$ in PTC cells. Thus, our data contribute to the understanding of the mechanism by which hormones effects on thyroid pathogenesis.

Recent studies have revealed that ERs play critical roles in the PTC development. ER $\alpha$ expression is usually increased in thyroid tumors, while ER $\beta$ expression is reduced when compared with normal parenchyma ${ }^{36,37}$. Estrogen-activated ER $\alpha$ mediates the stimulatory effects on PTC proliferation and migration, whereas ER $\beta$ has inhibitory actions ${ }^{8,15-17}$. In general, ER $\alpha$ promotes proliferation with an anti-apoptosis effect, while ER $\beta$ is related to apoptosis and growth inhibition. For this reason, the $E R \alpha / E R \beta$ ratio is helpful in elucidating the thyroid cancer pathophysiology $y^{6,7}$. However, ER $\beta$ expression was elevated in advanced prostate tumor tissues, which was associated with poor prognosis of hormone-naive patients ${ }^{38}$. Depletion of ER $\beta$ attenuated mammosphere formation ability in breast cancer cells and patient-derived breast cancer cells ${ }^{39}$. The fact that these two ERs have distinct distributions in the body and cell subpopulation indicates the different roles of ER $\alpha$ or ER $\beta$ maybe cancer-type and cell subpopulation-dependent ${ }^{40}$. Our study firstly reveals that ER $\beta$ is highly expressed in PTCSCs and contributes to PTCSC maintenance (Fig. 1). ER $\beta$ depletion remarkably reverses H19-mediated PTC 

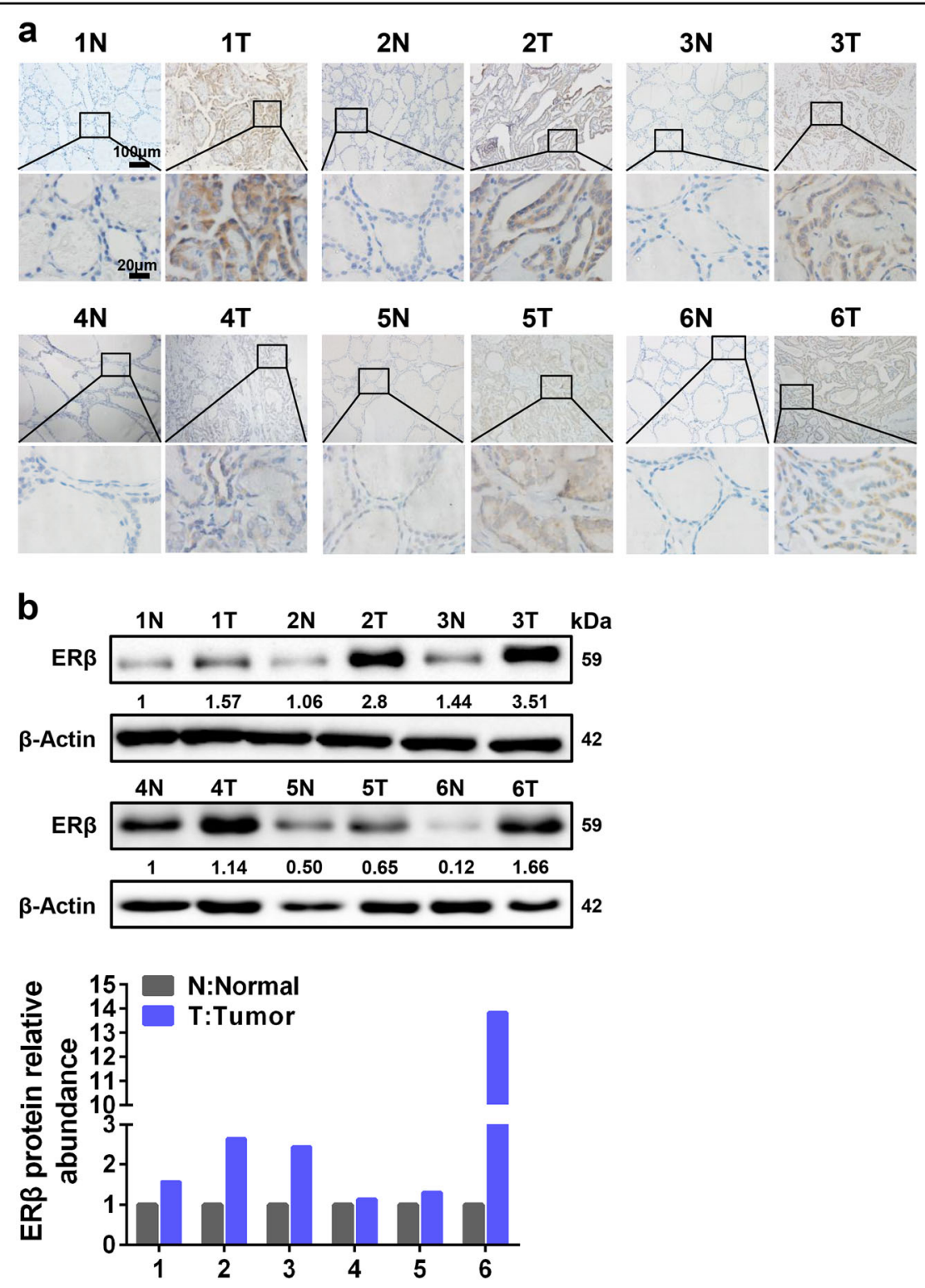

Fig. 5 ER $\beta$ expression is highly expressed in PTC tissue specimens. a Six pairs of PTC tissue specimens ( $(T)$ and adjacent normal tissue specimens (N) were subjected to IHC staining for ERß. Representative images were presented. Scale bar represents 100 or $20 \mu \mathrm{m}$. $\mathbf{b}$ ER $\beta$ expression was analyzed by western blotting in another six pairs of PTC tissues ( $\mathrm{T}$ ) and adjacent normal tissues (N) (upper panel). Fold change of ER $\beta$ expression was normalized to adjacent normal tissue in each pair (lower panel)

stem-like capability upon E2 treatment (Fig. 4). Our previous study has shown that $H 19$ functions as a competitive endogenous RNA (ceRNA) to sponge miRNA let7 , leading to the upregulation of HIF- $1 \alpha$ protein expres$\operatorname{sion}^{41}$. Here, we demonstrate that E2-induced $H 19$ acting as a ceRNA sponge miR-3126-5p to release ER $\beta$ expression. Furthermore, whether ER $\beta$, as a key transcriptional factor, transactivates self-renewal genes to maintain PTCSCs requires further exploration.

As ER $\beta$ has a critical role in regulating PTCSC maintenance, targeting ER $\beta$ could provide a novel therapeutic avenue for advanced PTC patients. A specific ER $\beta$ antagonist, 4-[2-phenyl-5,7-bis(trifluoromethyl)pyrazolo [1,5-a]pyrimidin-3-yl]phenol (PHTPP), has been shown to be effective in many cancer types. For examples, bladder cancer burden and mortality can be controlled by PHTPP treatment in the carcinogen-induced bladder cancer models $^{42}$. Consistently, PHTPP can also attenuate 27hydroxycholesterol-induced cell proliferation in prostate cancer cells ${ }^{43}$. However, the clinical application of PHTPP has been limited by its high toxicities and inferior selectivity ${ }^{39}$. In particular, a recent study has reported that 


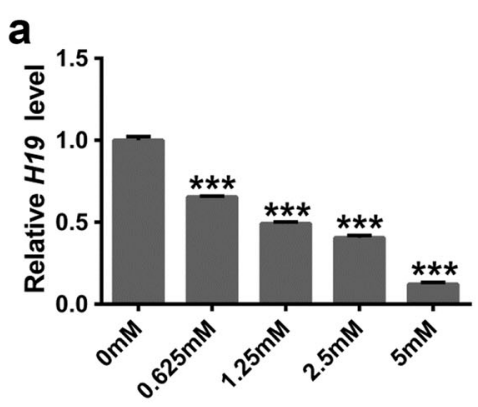

C

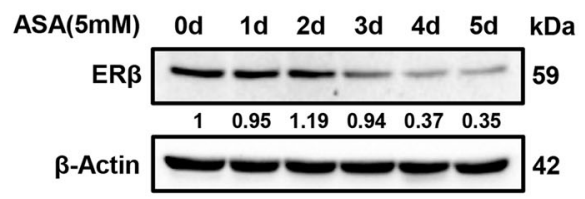

e
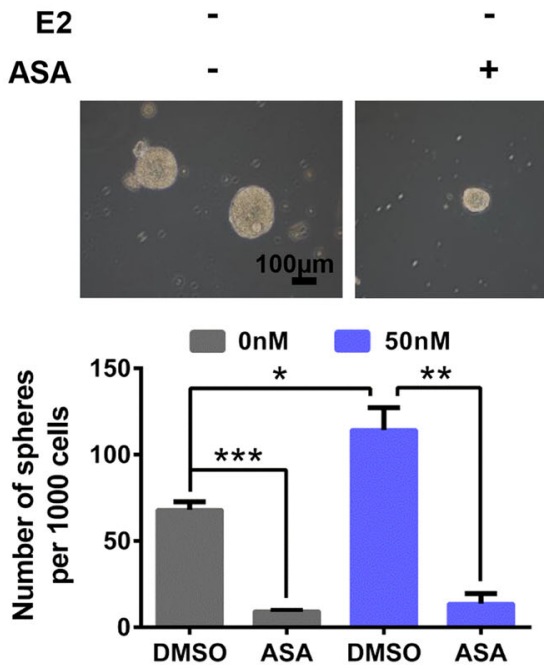

f

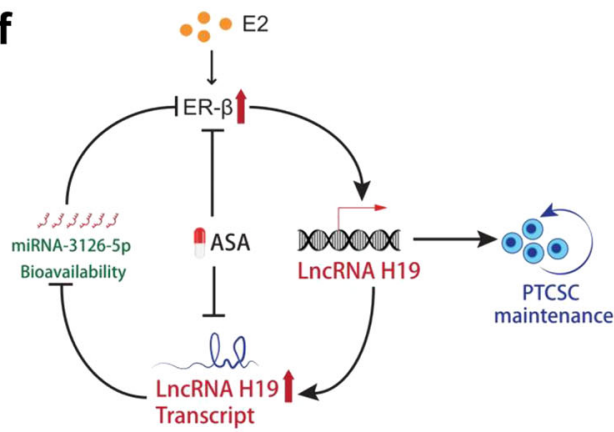

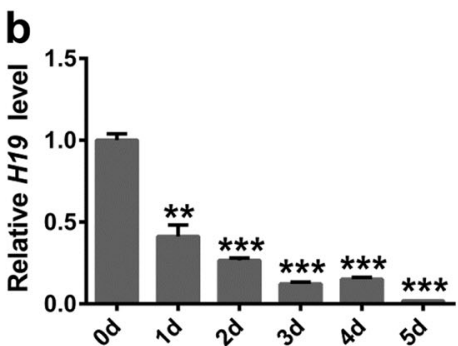

d
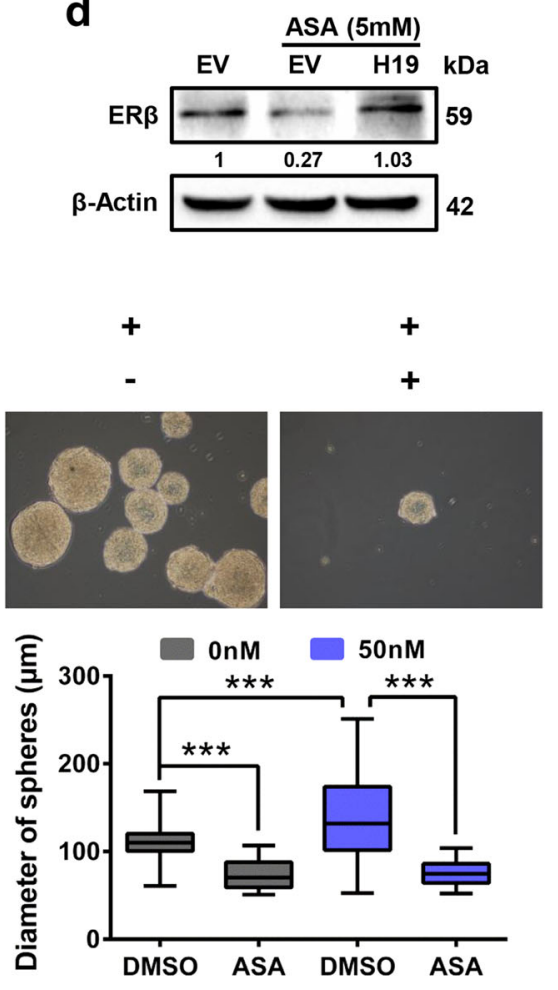

Fig. 6 (See legend on next page.)

treatment with PHTPP even promotes prostate cancer invasion $^{44}$. As a result, new medications are urgently needed to replace PHTPP for targeting ER $\beta$-induced
CSCs. Accumulative evidence has demonstrated that the FDA-proved anti-inflammatory drug aspirin (ASA) can exert inhibitory effects on CSCs. For example, aspirin can 
(see figure on previous page)

Fig. 6 Aspirin suppresses E2-induced cancer stemness through decreasing $\boldsymbol{H} 19$ and ER $\boldsymbol{\beta}$ expression. a K-1 cells were treated with aspirin for 3 days. The mRNA expression of $H 19$ was detected by RT-qPCR in different doses $(0,0.625,1.25,2.5$, and $5 \mathrm{mM})$ treatment. The relative $H 19$ level was normalized to ACTB. Data were shown as means \pm SD $\left(n=3,{ }^{* * *} P<0.001\right)$. b K-1 cells were treated with aspirin $(5 \mathrm{mM})$. The mRNA level of H19 was detected by RT-qPCR at different time points $(0,1,2,3,4$, and 5 days). The relative $H 19$ level was normalized to ACTB. Data were shown as means \pm SD $\left(n=3,{ }^{* *} P<0.01\right.$ and $\left.{ }^{* * *} P<0.001\right)$. c K-1 cells were treated with $5 \mathrm{mM}$ aspirin. The Expression of ER $\beta$ was detected by western blotting in different time points $(0,1,2,3,4$, and 5 days) treatment. $\beta$-Actin acted as the loading control. $\mathbf{d}$ K-1 cells were transfected with H19-overexpressing vector (H19) or empty vector (EV), ERß protein level was detected by western blotting in the absence or presence of ASA for 3 days. $\beta$-Actin acted as the loading control. e K-1 cells were treated with E2, aspirin and combination E2 with aspirin, sphere forming ability was analyzed. Representative images were presented, the scale bar represents $100 \mu \mathrm{m}$. The numbers and size of spheres were counted after culture for 10 days. Data were shown as means \pm SD. $\left(n=3,{ }^{*} P<0.05,{ }^{* *} P<0.01\right.$ and $\left.{ }^{* *} P<0.001\right)$. f Model for the E2-ERß-H19 underlies stem-like traits in papillary thyroid carcinoma

restrict cancer stem-like properties by decreasing the expression of stemness-related factors in pancreatic cancer and has no significant toxic effects on normal cells ${ }^{45}$. In addition, a previous study has also shown that aspirin inhibits breast cancer stem cell properties via targeting NF- $\mathrm{kB}$ signaling ${ }^{46}$. Notably, our findings were the first to demonstrate that aspirin markedly inhibits PTC stemness through decreasing both lncRNA H19 and ER $\beta$ expression (Fig. 6).

In summary, our studies reveal that ER $\beta-H 19$ positive feedback loop promotes PTC stem-like traits under E2 treatment. In addition, this novel PTCSC regulatory mechanism could be inhibited by the clinically approved medicine aspirin, thus providing a potential therapeutic opportunity for aggressive PTC.

\section{Materials and methods \\ Clinical samples}

Following informed consent from patients and approved by the Institutional Ethics Review Board of first Affiliated Hospital of Dalian Medical University, all PTC samples and PTC paraffin tissue specimens used in this study were obtained from the first Affiliated Hospital of Dalian Medical University. Samples were frozen in liquid nitrogen immediately after surgical resection for later mRNA and protein extraction.

\section{Cell lines}

The human thyroid cancer cell lines (TPC-1 and K-1) and 293T cells were purchased from American Type Culture Collection (ATCC, Manassas, VA, USA). The cell lines were authenticated at ATCC before purchase by their standard short tandem repeat DNA typing methodology. Each cell line was cultured in its standard medium as recommended by ATCC. TPC- 1 cells, K-1 cells, and 293T cells were maintained in Dulbecco's modified Eagle's medium (Invitrogen, Carlsbad, CA, USA) supplemented with $10 \%(\mathrm{v} / \mathrm{v})$ FBS. All cells were incubated at 37 ${ }^{\circ} \mathrm{C}$ in a humidified incubator containing $5 \% \mathrm{CO}_{2}$.

\section{Chemicals and E2 treatment}

All Chemicals including $17 \beta$-estradiol (E2), charcoal, and aspirin were obtained from Sigma (St. Louis, MO,
USA). E2 was dissolved in ethanol and aspirin was dissolved in DMSO following manufacturer's instructions. Before E2 treatment, cells were cultured in phenol redfree DMEM (Invitrogen, Carlsbad, CA, USA) medium supplemented with $10 \%$ charcoal-stripped FBS for three generations. Subsequently, we treated the cells with various concentrations of E2 as indicated and ethanol as vehicle control.

\section{Sphere formation assay}

Sphere formation assay was conducted in serum-free DMEM/F12 (Gibco, Carlsbad, CA, USA) supplemented with 2\% (v/v) B27 (Invitrogen, Carlsbad, CA, USA), 20 ng/ $\mathrm{ml}$ EGF (Sigma, St. Louis, MO, USA) and $20 \mathrm{ng} / \mathrm{ml}$ basic FGF (BD Biosciences, CA, USA). Dissociated single cells (600 or 1000) were seeded into $2 \mathrm{~mL}$ medium and propagated in six-well ultra-low attachment plates (Corning, NY, USA) and subsequently cultured at $37^{\circ} \mathrm{C}$ in $5 \% \mathrm{CO}_{2}$. Triplicate wells were set up. Sphere numbers were quantified at day 10 or 14 . The spheres greater than $50 \mu \mathrm{m}$ diameter were counted at $10 \times$ or $20 \times$ magnification under Olympus microscope.

\section{RNA extraction and RT-qPCR analysis}

Total RNA was extracted using Trizol reagent (Invitrogen, Carlsbad, CA, USA) following manufacturer's instructions, which was used to generate cDNA by using EasyScript One-Step gDNA Removal and cDNA Synthesis SuperMix Kit (TransGene Biotech, Beijing, China) with a random primer. RT-qPCR was performed using specific SYBR Select Master Mix (Invitrogen, Carlsbad, CA, USA) as recommended by the manufacturer. The relative mRNA levels were normalized to $A C T B$. The primers used were listed in Supplementary Table 1.

\section{Western blotting}

Cells were washed with ice-cold PBS and lysed in RIPA lysis buffer with freshly added cocktail protease inhibitor (Thermo Scientific, Rockford, IL, USA) on ice. Equal amounts of proteins were separated by SDSPAGE and transferred to nitrocellulose membranes (Millipore, County Cork, Ireland). The membranes were blocked with $5 \%$ fat-free milk in TBST at room 
temperature for $60 \mathrm{~min}$ and then incubated with indicated primary antibodies followed by incubation with peroxidase-conjugated secondary antibodies (Thermo Scientific, Rockford, IL, USA) at room temperature for $60 \mathrm{~min}$. The protein bands were detected and analyzed with an enhanced chemiluminescence kit (Amersham, Marlborough, MA, UK) using Bio-Rad ChemiDoc XRS ${ }^{+}$ Imaging System according to the manufacturer's instructions. The Primary antibodies were used as follows: mouse anti- $\beta$-Actin (Proteintech, Wuhan, China), rabbit anti-ER $\beta$ (Bioworld Technology, Louis Park, MN, USA), rabbit anti-OCT4 (Cell Signaling Technology, Danvers, MA, USA), rabbit anti-NANOG (Cell Signaling Technology, Danvers, MA, USA).

\section{IHC staining and scoring}

For this trial, PTC paraffin tissues were sectioned into 5 $\mu \mathrm{m}$ slices. SPlink Detection Kits (Biotin-Streptavidin HRP Detection Systems, ZSGB-BIO, Beijing, China) and a DAB Kit (ZSGB-BIO, Beijing, China) were used. Briefly, xylene and gradient ethanol were used for dewaxing and rehydration respectively. To block endogenous peroxidase activity, slides were immersed in $3 \%$ hydrogen peroxide for $10 \mathrm{~min}$. For epitope retrieval, slides were microwave treated in indicated target retrieval solution for $5 \mathrm{~min}$, three times. After blocking, the slides were incubated with the primary antibody of ER $\beta$ (Abcam, Cambridge, MA, USA), NANOG (Abcam, Cambridge, MA, USA), overnight at $4^{\circ}$ $\mathrm{C}$, respectively. Then the slides were incubated with the HRP-labeled anti-rabbit IgG secondary antibody for 30 min and HRP for $20 \mathrm{~min}$ at room temperature respectively. Subsequently, DAB was used to stain the slides. Finally, the slides were counterstained with hematoxylin, dehydrated with gradient ethanol. Images were taken at $20 \times$ and $100 \times$ magnification by Olympus microscope. The immunostaining was observed and scored by two independent experienced pathologists using light microscopy (magnification 20x). The intensity of staining and the proportion of positive cells were used to evaluate the immunostaining. The staining intensity was graded as follows: absent staining as " 0 ", weak staining as " 1 ", intermediate staining as " 2 ", and strong staining as " 3 ". The percentage of positive cells score was ranked from 0 to $100 \%$. Multiplying the percentage of positive cells score and the intensity score as the final score for each case. For ER $\beta, 67$ was the median level of the final scores of all cases. For NANOG, 57 was the median level of the final scores of all cases. Stained tissues with a final score $<$ median level was further classified as low, whereas tissues with a final score $\geq$ median level were determined as high.

\section{ALDH staining}

For ALDH staining, the $\mathrm{ALDH}^{+}$population was detected by ALDEFLUOR kit (Shanghai Stem Cell
Technology Co. Ltd, Shanghai, China) following the manufacturer's instructions. In brief, K-1 or TPC-1 (siNC and siER $\beta)$ cells $\left(1 \times 10^{6} / \mathrm{mL}\right)$ were analyzed on a BD C6 flow cytometer (USA) after staining in ALDH1 substrate containing assay buffer for $30 \mathrm{~min}$ at $37^{\circ} \mathrm{C}$ in dark. The negative control was treated with diethylaminobenzaldehyde (DEAB), a specific ALDH inhibitor.

\section{Xenograft assay}

K-1 (NTC and shER $\beta)$ cells $\left(1 \times 10^{6}\right)$ were subcutaneously injected into $\mathrm{BALB} / \mathrm{c}$ nude female mice (4-6 weeks old, $n=5$ ). The tumor volumes were measured by calipers once every three days, estimated using the formula $=0.5 \times a \times b^{2}$ ( $a$ and $b$ were the long and short diameter of the tumors respectively). After 23 days, the mice were sacrificed, and the tumor xenografts immediately dissected.

\section{Fluorescent in situ hybridization}

A fragment of $H 19$ designed as its probe was used and labeled with digoxigenin (DIG)-UTP (Roche, Mannheim, Germany) using the mMESSAGE T7 Ultra In Vitro Transcription kit (Ambion, Austin, TX, USA) in accordance with the manufacturer's directions. Slides were hybridized with probes overnight, washed twice with $50 \%$ formamide $/ 2 \times$ saline sodium citrate (SSC) and twice with $2 \times \mathrm{SSC}$ at $50^{\circ} \mathrm{C}$ for $5 \mathrm{~min}$ each time, then incubated with 1:500 diluted sheep anti-Dig (Invitrogen, Carlsbad, CA, USA) for $1 \mathrm{~h}$ at room temperature, followed by counterstained with DAPI $(1 \mu \mathrm{g} / \mathrm{ml})$, visualized using a confocal microscope (Leica, Wetzlar, Germany). Probe sequences were listed in Supplementary Table 1.

\section{Lentivirus infection and transient transfection}

Lentiviral-mediated short hairpin RNA (shRNA) directed against $H 19$ and ER $\beta$ were purchased from GenePharma, Suzhou, China. For shRNA lentiviruses infection, cells were infected in 6-cm dishes and subsequently split into $10-\mathrm{cm}$ dishes in the presence of $2 \mu \mathrm{g} / \mathrm{ml}$ puromycin (Sigma, St. Louis, MO, USA) for selection over $72 \mathrm{~h}$. The cells stably expressing shH19 or shER $\beta$ were chosen, respectively. shRNA sequence used were listed in Supplementary Table 1 . Transient transfection was performed by using Lipofectamine 3000 (Invitrogen, Carlsbad, CA, USA) according to the manufacturers' protocols.

\section{Plasmids}

Promoters of $H 19(-788 /+44), H 19(-502 /+44)$ were amplified from 293T genomic DNA and inserted into pGL3-Basic (Clontech, CA, USA) to generate the pGL3H19-WT $(-788 /+44)$ and pGL3-H19-Del $(-502 /+44)$, respectively. The E2 responsive element (ERE) was mutated (pGL3-H19-Mut) by site-directed mutagenesis using PCR. Sequence of ESR2 3'UTR was amplified from 293T cDNA 
and inserted into psiCHECK2 vector to generate psi-ESR2WT. The miRNA response element (MRE) of miR-3126-5p in ESR2 3'UTR region was mutated (psi-ESR2-Mut) by sitedirected mutagenesis using PCR. H19-expressing plasmids were constructed as previously described ${ }^{47}$. The miR-31265p binding sequence of $H 19$ mutation (H19-Mut) was generated by site-directed mutagenesis using PCR. pRLSV40 was purchased from (Clontech, CA, USA). All the primers used in plasmid construction were listed in Supplementary Table 1 .

\section{siRNAs, microRNA mimics, and microRNA inhibitors}

siRNAs specifically targeting ER $\beta$, siRNA control, miR127-5p, miR-876-3p, miR-1976, miR-3126-5p, miR-3198, miR-4268 mimics and negative control, miR-3126-5p inhibitor and negative control were all purchased from GenePharma, Suzhou, China. All sequences were listed in Supplementary Table 1.

\section{Dual-luciferase reporter assays}

Luciferase activity was measured using the DualLuciferase Reporter Assay system (Promega, Madison, WI, USA) according to the manufacturer's instructions. Growth media were removed, and cells were washed with cold PBS. Passive lysis buffer ( $200 \mu \mathrm{L}$ per well) was added with gentle rocking for $15 \mathrm{~min}$ at room temperature. Lysates $(50 \mu \mathrm{L})$ were transferred in black 96-well plate (Corning, NY, USA). Firefly and Renilla luciferase activity were assayed sequentially to the cell lysate in each well. For each luminescence reading, there would be a $2 \mathrm{~s}$ premeasurement delay after injector dispensing assay reagents into each well, followed by a $10 \mathrm{~s}$ measurement time. For pGL3 reporter system, transcriptional activity was calculated as the ratio of firefly luciferase activity (reporter) to Renilla luciferase activity (control). For psiCHECK2 reporter system, the RNA stability was calculated as the ratio of Renilla luciferase activity (reporter) to firefly luciferase activity (control). Results represented the average of triplicate samples from three independent experiments.

\section{Statistical analysis}

Data were expressed as means \pm SD of three independent experiments with GraphPad Prism software. The Student's $t$-test was used to make a statistical comparison between groups. Pearson's correlation test was used to examine the correlation between ER $\beta$ and NANOG by IHC staining. Statistical Package for Social Sciences (SPSS) software (version 24.0) was used for Statistical analysis in this study. ${ }^{*} P<0.05,{ }^{* *} P<0.01$ and ${ }^{* * *} P<0.001$ were considered statistically significant.

\section{Acknowledgements}

We thank Quentin Liu's lab members for their critical commends and technical support. This research work was supported by Innovative Research Team in University of Ministry of Education of China (No. IRT_17R15), National Natural
Science Foundation of China (No.81630005 to QL, No.81573025 to QL, No. 81402445 to C-LW, No. 81402071 to D-PL, No. 81502579 to Z-JH, No. 81502594 to H-JW, No. 81602585 to F-MZ, No. 81703062 to LH, and No. 81703091 to FA), Dalian high-level talent innovation program (2016RD12 to QL) and International scientific and technological cooperation of Dalian (2015F11GH095 to QL). EW-F Lam's work is supported by MRC (MR/N012097/ 1), CRUK (A12011), Breast Cancer Now (2012MayPR070; 2012NovPhD016), the Cancer Research UK Imperial Centre, Imperial ECMC and NIHR Imperial BRC.

\section{Author details}

${ }^{1}$ The First Affiliated Hospital, Institute of Cancer Stem Cell, Dalian Medical University, Dalian, China. ${ }^{2}$ State Key Laboratory of Oncology in South China, Cancer Center, Sun Yat-sen University, Guangzhou, China. ${ }^{3}$ Dongfang Hospital, Key Laboratory of Health Cultivation of the Ministry of Education, Beijing University of Chinese Medicine, Beijing, China. ${ }^{4}$ Department of Pathology, The First Affiliated Hospital of Dalian Medical University, Dalian, China. ${ }^{5}$ Dalian Municipal Women And Children's Medical Center, Dalian, China. ${ }^{6}$ Departmemt of Pathology, Dalian Medical University, Dalian, China. ${ }^{7}$ Department of Surgery and Cancer, Imperial College London, London W12 ONN, UK

Conflict of interest

The authors declare that they have no conflict of interest.

\section{Publisher's note}

Springer Nature remains neutral with regard to jurisdictional claims in published maps and institutional affiliations.

Supplementary Information accompanies this paper at (https://doi.org/ 10.1038/s41419-018-1077-9).

Received: 8 February 2018 Revised: 19 August 2018 Accepted: 13 September 2018

Published online: 02 November 2018

\section{References}

1. Massoni, F., Simeone, C., Ricci, P., Onofri, E. \& Ricci, S. Papillary thyroid carcinoma and medicolegal considerations. Minerva Med. 104, 493-494 (2013).

2. Han, S. A., Jang, J. H., Won, K. Y., Lim, S. J. \& Song, J. Y. Prognostic value of putative cancer stem cell markers (CD24, CD44, CD133, and ALDH1) in human papillary thyroid carcinoma. Pathol. Res. Pract. 213, 956-963 (2017).

3. Ahn, S. H., Henderson, Y. C., Williams, M. D., Lai, S. Y. \& Clayman, G. L. Detection of thyroid cancer stem cells in papillary thyroid carcinoma. J. Clin. Endocrinol. Metab. 99, 536-544 (2014).

4. Giuffrida, R. et al. Resistance of papillary thyroid cancer stem cells to chemotherapy. Oncol. Lett. 12,687-691 (2016).

5. Lin, Z. et al. Association of cancer stem cell markers with aggressive tumor features in papillary thyroid carcinoma. Cancer Control 22, 508-514 (2015).

6. Santin, A. P. \& Furlanetto, T. W. Role of estrogen in thyroid function and growth regulation. J. Thyroid Res. 2011, 875125 (2011).

7. Zhang, L. et al. Estrogen stabilizes hypoxia-inducible factor 1a through $G$ protein-coupled estrogen receptor 1 in eutopic endometrium of endometriosis. Fertil. Steril. 107, 439-447 (2017).

8. Dong, W. et al. Estrogen induces metastatic potential of papillary thyroid cancer cells through estrogen receptor $a$ and $\beta$. Int. J. Endocrinol. 2013 941568 (2013).

9. Zane, M. et al. Estrogen and thyroid cancer is a stem affair: a preliminary study. Biomed. Pharmacother. 85, 399-411 (2017).

10. Gong, W. et al. Knockdown of NEAT1 restrained the malignant progression of glioma stem cells by activating microRNA let-7e. Oncotarget 7, 62208-62223 (2016).

11. Peng, F. et al. H19/let-7/LIN28 reciprocal negative regulatory circuit promotes breast cancer stem cell maintenance. Cell Death Dis. 8, e2569 (2017).

12. Wang, $X$. et al. Long non-coding RNA DILC regulates liver cancer stem cells via IL-6/STAT3 axis. J. Hepatol. 64, 1283-1294 (2016).

13. Qiu, J. J. et al. ElncRNA1, a long non-coding RNA that is transcriptionally induced by oestrogen, promotes epithelial ovarian cancer cell proliferation. Int. J. Oncol. 51, 507-514 (2017). 
14. $\mathrm{Hu}, \mathrm{Q}$. et al. 17ß-Estradiol treatment drives Sp1 to upregulate MALAT-1 expression and epigenetically affects physiological processes in U2OS cells. Mol. Med. Rep. 15, 1335-1342 (2017).

15. Fan, D. et al. Estrogen receptor a induces prosurvival autophagy in papillary thyroid cancer via stimulating reactive oxygen species and extracellular signal regulated kinases. J. Clin. Endocrinol. Metab. 100 E561-571 (2015).

16. Huang, Y. et al. Differential expression patterns and clinical significance of estrogen receptor- $a$ and $\beta$ in papillary thyroid carcinoma. BMC Cancer 14, 383 (2014).

17. Chu, R. et al. The cross-talk between estrogen receptor and peroxisome proliferator-activated receptor gamma in thyroid cancer. Cancer 120, 142-153 (2014).

18. Jung, J. W. et al. Metformin represses self-renewal of the human breast carcinoma stem cells via inhibition of estrogen receptor-mediated OCT4 expression. PLOS ONE 6, e28068 (2011).

19. Xu, S., Chen, G., Peng, W., Renko, K. \& Derwahl, M. Oestrogen action on thyroid progenitor cells: relevant for the pathogenesis of thyroid nodules? J. Endocrinol. 218, 125-133 (2013).

20. Sun, $\mathrm{H}$. et al. H19 IncRNA mediates $17 \beta$-estradiol-induced cell proliferation in MCF-7 breast cancer cells. Oncol. Rep. 33, 3045-3052 (2015).

21. Bhan, A. et al. Antisense transcript long noncoding RNA (IncRNA) HOTAIR is transcriptionally induced by estradiol. J. Mol. Biol. 425, 3707-3722 (2013).

22. Qiu, J. J. et al. Expression and clinical significance of estrogen-regulated long non-coding RNAs in estrogen receptor a-positive ovarian cancer progression. Oncol. Rep. 31, 1613-1622 (2014).

23. Chakravarty, D. et al. The oestrogen receptor alpha-regulated IncRNA NEAT1 is a critical modulator of prostate cancer. Nat. Commun. 5, 5383 (2014).

24. Peng, W. X., Huang, J. G., Yang, L., Gong, A. H. \& Mo, Y. Y. Linc-RoR promotes MAPKJERK signaling and confers estrogen-independent growth of breast cancer. Mol. Cancer 16, 161 (2017).

25. $\mathrm{Xu}, \mathrm{N}$. et al. Clinical significance of high expression of circulating serum IncRNA RP11-445H22.4 in breast cancer patients: a Chinese population-based study. Tumour Biol. 36, 7659-7665 (2015).

26. Knoll, M., Lodish, H. F. \& Sun, L. Long non-coding RNAs as regulators of the endocrine system. Nat. Rev. Endocrinol. 11, 151-160 (2015).

27. Hatchell, E. C. et al. SLIRP, a small SRA binding protein, is a nuclear receptor corepressor. Mol. Cell 22, 657-668 (2006).

28. Braganza, M. Z. et al. Benign breast and gynecologic conditions, reproductive and hormonal factors, and risk of thyroid cancer. Cancer Prev. Res. 7 , 418-425 (2014)

29. Xhaard, C. et al. Menstrual and reproductive factors in the risk of differentiated thyroid carcinoma in young women in France: a population-based casecontrol study. Am. J. Epidemiol. 180, 1007-1017 (2014).
30. Zeng, Q., Chen, G. G., Vlantis, A. C. \& van Hasselt, C. A. Oestrogen mediates the growth of human thyroid carcinoma cells via an oestrogen receptor-ERK pathway. Cell Prolif. 40, 921-935 (2007).

31. Rajoria, S. et al. Metastatic phenotype is regulated by estrogen in thyroid cells. Thyroid 20, 33-41 (2010).

32. Nakada, D. et al. Oestrogen increases haematopoietic stem-cell self-renewal in females and during pregnancy. Nature 505, 555-558 (2014).

33. Lan, $\mathrm{X}$. et al. Downregulation of long noncoding RNA H19 contributes to the proliferation and migration of papillary thyroid carcinoma. Gene 646, 98-105 (2018).

34. Basak, P. et al. Estrogen regulates luminal progenitor cell differentiation through H19 gene expression. Endocr. Relat. Cancer 22, 505-517 (2015).

35. Klein, R. H. et al. Cofactors of LIM domains associate with estrogen receptor a to regulate the expression of noncoding RNA H19 and corneal epithelial progenitor cell function. J. Biol. Chem. 291, 13271-13285 (2016).

36. Magri, F. et al. Expression of estrogen and androgen receptors in differentiated thyroid cancer: an additional criterion to assess the patient's risk. Endocr. Relat. Cancer 19, 463-471 (2012).

37. Chen, G. G., Vlantis, A. C., Zeng, Q. \& van Hasselt, C. A. Regulation of cell growth by estrogen signaling and potential targets in thyroid cancer. Curr. Cancer Drug Targets 8, 367-377 (2008).

38. Zellweger, $\mathrm{T}$. et al. Estrogen receptor $\beta$ expression and androgen receptor phosphorylation correlate with a poor clinical outcome in hormone-naive prostate cancer and are elevated in castration-resistant disease. Endocr. Relat. Cancer 20, 403-413 (2013).

39. $\mathrm{Ma}$, R. et al. Estrogen receptor $\beta$ as a therapeutic target in breast cancer stem cells. J. Natl. Cancer Inst. 109, 1-14 (2017).

40. Warner, M., Huang, B. \& Gustafsson, J. A. Estrogen receptor $\beta$ as a pharmaceutical target. Trends Pharmacol. Sci. 38, 92-99 (2017).

41. Peng, F. et al. Glycolysis gatekeeper PDK1 reprograms breast cancer stem cells under hypoxia. Oncogene 37, 1062-1074 (2017).

42. Hsu, I. et al. Suppression of ER $\beta$ signaling via ERß knockout or antagonist protects against bladder cancer development. Carcinogenesis 35, 651-661 (2014).

43. Raza, S. et al. The cholesterol metabolite 27-hydroxycholesterol stimulates cell proliferation via ERß in prostate cancer cells. Cancer Cell Int. 17, 52 (2017).

44. Mak, P. et al. ERbeta impedes prostate cancer EMT by destabilizing HIF-1alpha and inhibiting VEGF-mediated snail nuclear localization: implications for Gleason grading. Cancer Cell 17, 319-332 (2010).

45. Zhang, Y. et al. Aspirin counteracts cancer stem cell features, desmoplasia and gemcitabine resistance in pancreatic cancer. Oncotarget 6, 9999-10015 (2015).

46. Kastrati, I. et al. A novel aspirin prodrug inhibits NFkB activity and breast cancer stem cell properties. BMC Cancer 15, 845 (2015).

47. Kallen, A. N. et al. The imprinted H19 IncRNA antagonizes let-7 microRNAs. Mol. Cell 52, 101-112 (2013). 